\title{
Environment-shaping: An Alternative Approach to Applying Foreign Development Assistance
}

\section{Elon Weinstein and Keith G. Tidball}

\begin{abstract}
Development assistance has a chequered past, in large part because planning for development assistance is historically such a fractured enterprise internally, and so disassociated from development assistance recipients' assets and needs. The authors of environment-shaping offer an alternative development programme planning methodology that highlights above all else the ever-important relationship between development assistance and the environment into which it is offered. The authors employ an asset-based, rather than a traditional deficit-based, approach to assessing the environment for which development assistance will be formulated. The authors then highlight the power of perceptions in the creation of policy programming and in identifying and reinforcing opportunities for positive feedback loops within the recipient environment as critical to truly 'sustainable' development.
\end{abstract}

Keywords asset-based post-conflict development; environment-shaping; fragile states; peacekeeping planning; sustainable development planning

\section{Introduction}

Only when aid policy programming effectively accounts for the environment in which it is delivered can 'sustainable' growth and development actually be achieved. Though many official strategies for development and post-conflict reconstruction exist, none effectively describe a methodology for bridging strategic objectives and operations. As a result operational planning proceeds along an ad hoc path with mixed, and usually short-term, results. Similarly, bureaucratic institutions responsible for development and post-conflict strategy writing and implementation are aligned in ways that reinforce narrow bureaucratic divisions and reward resource-driven programming. The US Institute for Peace highlights that: 'Evidence from many transitional and post-conflict environments reveals that piecemeal reforms tend to fail. Reconstruction involves interdependent tasks, so reconstruction strategies must be coherent and integrated.' (USIP 2005: 9) Environment-shaping is an alternative approach that bridges strategy and operations by recognizing the importance of accounting 
for the environment to which aid will be delivered in the formulation of strategic and operational objectives from the very beginning of the planning process.

In this essay the authors first highlight the importance of defining strategic objectives. Then, we describe our concept of environment-shaping methodology, in which we turn to asset-based participatory analysis to discover existing resources and assets, indigenous desires and perceptions, enablers - including individuals who can serve in a catalytic role, existing positive feedback loops and opportunities for future positive feedback loops, and measures of the intended target environment's receptiveness to assistance. Third, detailed operational objectives are spelled out based on the earlier asset-based analysis. Fourth, a critical path is mapped for each operational objective, identifying barriers and dependencies and the relative timeline for each task. Fifth, an operational plan is designed to maximize existing assets, and focus on aligning programme design to the environment's receptiveness by actively addressing dependencies and reinforcing enablers. At this important stage expected perceptions are a driving factor behind the shape of specific programmes, and even whether or not a programme will be implemented.

An environment-shaping methodology addresses not just aid itself, but the environment in which that aid will be delivered. By tightly relating direct and indirect assistance to its recipient environment, or shaping the recipient environment when necessary, environment-shaping can maximize the potential for success. Furthermore, as environment-shaping is holistically objectivedriven, it not only ignores traditional barriers to successful aid programmes, but provides the means both to identify, and relate operationally any critical element of relevance to the objective regardless of what sector that element is normally associated with.

\section{Post-Conflict Reconstruction}

The post-conflict world is as complex and fluid an environment as any policy makers or planners might face. Issues related to the creation of new national military and police forces, to writing of constitutions, to delivering women's health services, to preparing for elections, to establishing government institutions, developing programmes to teach children how to read, and everything in between, these 'nation-building' tasks require careful prioritization and expenditure of limited aid resources. Given these limited resources, be they human capital, expertise, equipment or money, resources will always be scarcer than needs demand. The process of selecting which tasks to undertake by necessity means deselecting other tasks. Deselecting also responds to what frequently is the most precious resource of all - time.

While many practitioners have expended great energy in writing and lecturing about, and planning for discrete areas within the scope of post-conflict reconstruction, few have attempted a comprehensive methodology for prioritizing the many tasks required and understanding the effect these different tasks 
have on each other. We do not attempt to explain why this is, but are satisfied in recognizing that the beginnings are there. The most prominent and ambitious effort to date is the Center for Strategic and International Studies 'Post-Conflict Reconstruction Task Framework', published in May 2002. While this generically useful document, organized into the four 'pillars' of Security, Justice and Reconciliation, Social and Economic Well Being, and Governance and Participation (with the perfunctory addition of Cross-Cutting Tasks) has great utility in identifying the world of possible tasks, ultimately it is little more than a list. CSIS excuses itself from introducing any methodology for prioritizing this expansive list because 'countries emerge from conflict under differing and unique conditions. Therefore, the priority, precedence, timing, appropriateness, and execution of tasks will vary from case to case.' (CSIS 2002: 2)

The United Nations Development Group and the World Bank have jointly formulated what they call the Transitional Results Matrices or TRM, a 'resultsbased framework' that makes considerable strides towards cross-sector integration, identification of critical barriers to key development goals, and host-country 'ownership' in the transitional post-conflict phase or in the consolidation of a fragile state, but ultimately it seems to fall just short on all of these counts (UNDG/WB 2005). In the end the three applied TRM cases of the Central African Republic, Liberia and East Timor appear as if drawn directly from the CSIS Task framework, a testament to CSIS influence in the post-conflict planning community. Unfortunately, though fairly comprehensive, the TRM cases mostly share negative attributes with the Task Framework, such as categorization by broad sectors with unclear relationships between either the sectors themselves (security, governance, economic management and social service delivery) or the tasks within the sectors, and a lack of a participatory component with convincing depth.

\section{Development}

In January 2005 the United States Agency for International Development (USAID) published its Fragile States Strategy, a nascent document recognizing that environmental factors play a role in the success or failure of assistance inputs by focusing on 'reform related to the conditions that are driving fragility and that will increase the likelihood of long-term stability' and 'the underlying sources of fragility' (USAID 2005: 5). While acknowledging that chaotic national development environments require different approaches than more ordered ones is commendable, this new strategy is not a sufficiently detailed prescription to offer much guidance to policy makers forced to 'select' one task and 'deselect' another. In keeping with Roland Paris' 'Institutionalization before Liberalization', 2 USAID's Fragile States Strategy appears to offer a one-size-fits-all prescription that focuses ultimately on formal institution building under the assumption that, by definition, a state that is fragile must have weak governing institutions. Despite several 'Illustrative Programmatic Options', such as 
strengthening civil control of the military, reforming and building 'technical and administrative capacity of those parts of the civil service responsible for economic management, core services, and food security', the Fragile States Strategy also does not specify how to appropriately apply development resources so as to 'bring this vision to reality' (USAID 2005: 7-9). The bridge between strategic vision and operational reality remains un-built.

Like the CSIS Task Framework, the Fragile States Strategy highlights the 'uniqueness and inherent complexity of these environments' (USAID 2005: 5). While every post-conflict or 'fragile state' is a unique case, it is also true that the same principles of human and institutional behaviour recur in post-conflict environments with remarkable consistency everywhere in the world - Asia, Africa, Latin America and Europe - time and time again. ${ }^{3}$ Furthermore, the bureaucratic and planning challenges that governments and NGOs face are virtually identical regardless of what geographic region captures their attention at the moment. The view that every case is unique and therefore requires a discrete approach is widespread and is a cultural fixture into the vast majority of US Government agencies that deal with these issues. Geographic bureaus, for example, dominate the State Department, while functional bureaux operate on the periphery of policy making largely in a supporting role. Lessons from one region are rarely learned by those working on another region since no mechanisms exist to pass functional (technical) information from one geographically-based planning effort to another. One result of this gap is a lack of analytical methodology. Instead 'nation-building' development tasks become selected or deselected almost exclusively on an ad hoc basis. The 'products' are predictably disappointing.

Take Liberia, for example. In late 1997 Liberia reverted from recovery to combat following 'free and fair' elections despite concerted efforts by ECOMIL (the Nigerian-led military component of the Economic Community of West African States' Mission to Liberia) and the 2003 United Nations Mission to Liberia (UNMIL), USAID and other international aid agencies and NGOs. Following virtually complete state collapse under the stress of ongoing civil war, ECOWAS, the UN, aid agencies and NGOs returned, hoping that the second time around they would get it right. And yet there were gaps in the design and realization of the demobilization, disarmament and reintegration (DDR) programmes mirroring the failings witnessed only three years earlier in neighbouring Sierra Leone. At this date several high-ranking Sierra Leonean RUF commanders are known to still retain harems of girls captured during the war. When they reported to demobilization camps for processing they claimed enslaved women as 'family'. Nowhere in the process were provisions made to test the validity of 'family'. Shockingly, several years later in Liberia, similarly designed programmes ignored the same problem, leaving girls and women captured by combatants unable to free themselves even years after combat has ceased. In one of many examples, during demobilization in both Sierra Leone and Liberia, combatants' 'wives' many of whom were actually abducted into servitude, sexual and otherwise remained under the charge of their abductors despite combatants moving 
through a formal UN-run demobilization programme. Not surprisingly the failure to address these women's needs coincided with institutional gaps. UNICEF wouldn't take responsibility for someone over the age of 18. The United Nations Department of Peacekeeping Operations (UNDPKO) took no interest in women who were not combatants. Once again, an existing resource base and traditional institutional divisions of labour dictated 'needs' on the ground, rather than the other way around, leaving obvious tragic human needs unmet.

Similarly DDR in the Democratic Republic of the Congo stumbled because institutional constraints limited meaningful security sector reform despite the fact that DDR planners intended to funnel a significant percentage of combatants into a new security sector, and warnings from the same planners that failure to address the security sector would likely doom the entire effort. For example in 2002 the World Bank established the Multi-Country Demobilization and Reintegration Program (MDRP) for the 'Greater' Great Lakes, a \$500 million trust ostensibly for DDR. Surprisingly, within a fairly short period the Fund was flush, but the World Bank explicitly targets 'ex-combatants', meaning that the MDRP will not touch combatants until after they are disarmed and demobilized, leaving the critical disarmament and demobilization pieces, and the ultimate fate of DDR in the Congo, in others' hands, and the process fractured. In fact DDR processes throughout the world provide ready examples of one of the most prominently repeated failures of institutions to adapt to operational requirements for success. Security institutions rightfully dominate disarmament and demobilization, while development and finance agencies and banks adopt reintegration - to the degree it is addressed at all. In the course of a normal day these two worlds of security and development virtually never cross paths. They speak different languages, sport different cultures, exercise different prerogatives, generally see the world through completely different lenses and therefore famously fail to account for the implications of their respective actions on each other. The problem, of course, is that to have a successful DDR process the individual combatant (hopefully soon to be ex-combatant) must move through an uninterrupted continuum lest his doubts and disappointed expectations lead him to reignite conflict out of fear, desperation or hunger.

The 2002 ceasefire in Burundi almost came to naught for just this reason. The largest rebel group and the government signed a ceasefire and, as called for in the agreement, the rebels began moving to cantonment areas where, once assembled, they expected to be fed until the DDR process began. They waited but no food arrived. Meanwhile the US government wrung its hands. Though achieving this ceasefire had been a stated US policy objective, the US government was completely unprepared to respond now that ink was actually drying on an agreement. Because the rebels were still 'combatants' they were legally off limits to humanitarian agencies. USAID therefore could do nothing. That left US military assistance via slow and cumbersome mechanisms that could take months to put food in the hands of the hungry soldiers. Days passed. The rebels grew hungry and began to forage. Inevitably the foraging rebels encountered patrolling government troops. Firefights broke out followed by 
accusations on both sides of violations of the ceasefire. It looked like war might break out all over again until the German government, convinced of the direness of the situation, finally agreed to provide a week or so of rations to the cantoned rebels. Should not the US be able to respond to the success of long-standing policy it had years to prepare for? There is an alternative.

\section{What is 'Environment-shaping?'}

While useful as a starting point, the CSIS Task Framework must introduce a methodology for selecting and prioritizing tasks in order to be of more than marginal analytical benefit. It does, however, comport with the US government's approach to national development programmes in that most USAID national programmes are divided out by function. Within USAID, the most extreme internal division remains between those concerned with emergency humanitarian relief and those whose purpose is to address long-term development. The Office of Foreign Disaster Assistance (OFDA) manages the logistics of the food 'pipeline' and food distribution, while the 'rest' of USAID develops policy and manages contracts with implementers with the goal of 'development'. Less extreme divisions within the development community are also commonplace. Sectors are largely treated independently from one another. Whether government institution building, community development, health programmes, female or adult education, small business promotion, or what have you, the relationship between these sectors is rarely defined, and therefore even more rarely accounted for in the design of the programmes themselves.

For the purposes of this essay, to clarify how environmental-shaping would relate to and impact upon existing policy frameworks, development assistance can be broken down into two categories: direct assistance and indirect assistance.

Direct assistance is delivered directly to the recipient for immediate consumption, usage or employ. This type of assistance, such as food aid, medical supplies and treatment, heating fuel, or shelter, is characterized by its shortterm nature. There are no expectations that direct assistance will have longterm development impacts, though it might alleviate hunger, sickness, cold or rain. In most cases direct assistance is composed of consumables such as foodstuffs, portable short-lived equipment or devices such as the water purifying Reverse Osmosis Purification Units (ROPU), or tents and other temporary shelter. Certain forms of assistance, such as seeds, rakes and hoes or even micro-loans are delivered with an expectation of some medium-term effects, but are highly localized, or even individual in impact. In security sectors direct assistance includes the provision of foreign troops, police or gendarme, or military advisors to provide security in the absence of indigenous security capabilities.

Indirect assistance is not delivered directly to the population of a country, but instead focuses on governments or other institutions designed to deliver services or provide for social, economic or security needs. Thus indirect assistance 
includes support for a government's institutional capacity in any sector be it an education or finance ministry, 'train and equip' programmes for new military and police forces, and assistance in setting up indigenous systems for waste collection or delivery of medical services. Indirect assistance is not necessarily given with a government in mind. Local NGO or 'civil society' capacity building programmes are also often the targets of indirect assistance.

'Environment-shaping' is both a third development category - a second order of indirect assistance - and, by consequence, a broader development methodology that incorporates development tasks from the first two categories described above.

There are two levels to 'environment-shaping'. First, 'environment-shaping' is simply the set of those development tasks that in concert create an enabling environment for development and growth, security, peace, stability, societal healing, etc. These might include chambers of commerce, roads and public telecommunications, common-sense legislative regimes that introduce order and modes of behaviour without being overly restrictive, or promoting business models that seek multi-ethnic production and supply chains that take best advantage of existing locals skills, infrastructure and markets. Secondly, 'environment-shaping' is the alignment of direct and indirect assistance to a receptive environment by shaping the recipient environment simultaneously with assistance programmes. Environment-shaping must occur at the state, regional, local and individual levels. Ultimately the success or failure of a development proposition rests with human behaviour - to the receptiveness of people to an idea. That behaviour is itself motivated by perceptions of cost and benefit to the individuals. Later, we will address the necessity to account for (usually perception-driven) self-reinforcing growth trends, or positive feedback loops.

The aim of this third category is three-fold. Firstly, to 'grease the skids' by reducing transaction costs, minimizing input factor costs where possible, and eliminating outright barriers to all elements of trade, production, travel and communication. The World Bank Group ranks countries according to the difficulty of doing business. Categories include: 'Starting a Business; Hiring and Firing Workers; Registering Property; Getting Credit; Protecting Investors; Enforcing Contracts; and Closing Business.' Not surprisingly, in post-conflict countries such as Angola, business is both risky and expensive. For example, 'Starting a Business' (in the formal economy) in Angola took on average 14 procedures over a 146 day period, while 'Registering Property' took eight procedures over a duration of 335 days. Enforcing a contract in Angola required a whopping 47 procedures over 1,011 days. Similarly, endemic corruption in postconflict countries limits private sector development through high transactions costs. In Sierra Leone, for example, starting a business only takes 26 days (compared with Haiti's high of 203 days), but costs 1,268 per cent of per capita Gross National Income (GNI), mostly in bribes (WB et al. 2005). Environment-shaping, not to be confused simply with macro-economic liberalization, seeks to make growth - and ultimately development-producing societal interactions - as frictionless as possible, whether that means simply building 
roads or telecommunications infrastructure, encouraging economic communication through energized markets, or strenuous long-term community-knitting exercises that slowly create opportunities for intra-community communication and interaction. In many respects environment-shaping will entail greater regulation and government intervention in some areas, just as government regulations and development barriers are lifted in other areas.

Secondly, an environment-shaping approach specifically targets areas that are fundamental to enabling growth such as a sound and comprehensive property rights regime. Though we will address this illustrative example in greater detail later, a property rights regime is an important environment-shaper because it enables individuals and collectives to realize and leverage the secondary value of assets into growth. Thus the introduction of a property rights regime alters the nature of capital, a primary component of the societal and economic environment.

Thirdly, environment-shaping seeks to alter the nature of the physical environment in which a community lives and works to one in which positive societal inputs are mirrored back by their physical surroundings. Thus, in psychological terms environment-shaping validates the efforts of the members of a society to better their lot with physical positive feedback. This feedback may include beautification, such as repair and painting of run-down neighbourhoods, urban greening, public lighting or effective public waste management. Each of these three 'meanings' for environment-shaping will be presented in more detail shortly.

\section{Methodology of Environment-shaping}

The traditional approach to post-conflict planning identifies the complete list of tasks to 'build a nation' and then prioritizes those tasks in the absence of a clear rational methodology for doing so. Often this prioritization process is driven in reverse by resource constraints: those things donors have the money for are de facto the highest priorities. Problematically, this approach most often fails to focus on the primary drivers of growth and development, or does so only coincidentally. A more effective approach is to first develop a detailed 'end state' (this is the target) through an asset-based participatory process that communicates the attributes of an ideal environment for growth, peace, development, security and self-sustainability, and from that identify the critical paths of dependencies to achieving that end state.

A critical path is the set of tasks in operational order that accomplishment of an end state depends upon (Lockyer 1964). Each task along a critical path is a dependency. A land tenure system in Sudan is a critical path to security and development objectives. Why? Because the Sudanese tell us: first, land rights are one of the 'root causes' of the conflict in Sudan and a fuse for future conflict; secondly, land tenure issues must be resolved in order to prevent conflict between returning refugees and IDPs and current landholders, to deliver 
humanitarian relief, and to supply short-term self-sustainment and community reintegration. In the words of a USAID official responding to the need to encourage agricultural production in Sudan to improve food security: 'Valorizing agricultural production in the absence of a lawful environment encourages land grabs' (InterAction 2004); and, thirdly, economic development is ultimately reliant on the secondary value of assets, such as land (De Soto 2000). Therefore land tenure is a critical path ${ }^{4}$ for conflict settlement, conflict prevention, management of refugee and IDP returns and economic growth.

Land tenure is one of the best examples of the 'real world' programming and funding implications of adopting an environment-shaping approach over more traditional approaches. Land tenure requires four components: 1) law (parliamentary bodies), 2) arbitration (judiciary), 3) record-keeping and verification (institution building), and 4) enforcement (police and penal facilities). The result of adopting an environment-shaping approach is twofold. First, certain tasks are given a higher priority than they would by using a traditional approach. Policing, for example, is of the highest priority for land tenure, whereas we might consider it secondary if viewed generically. Secondly, the resource requirements for the police sector are much smaller with a 'critical path' approach than with a traditional approach because in one case we are only seeking to police a specific function (land rights), while the 'traditional' approach views the policing sector generically (all civil security functions). The same holds true for the other requirements of a land tenure system such as the judiciary and government institutions.

A land tenure system is not the only critical path to the end state. Other critical paths may also have components that overlap those of land tenure. The delivery of health services may also require record-keeping, for example, so programmes aimed at building government institutions would concentrate first on land and health-related record-keeping and verification. Likewise, civil security requirements are almost certain to be broader than simply enforcing land claims, so policing requirements might include other functions as well. Limited successes in these areas then serve as the foundation for broader development of police, judiciary, institutions, law writing, et cetera.

Importantly, environment-shaping is not restricted simply to the macro, or national scale. Take female education in Southern Sudan. Where an estimated 80 per cent of adults, 60 per cent or more of whom are women, are illiterate, USAID naturally promotes schooling. Current development efforts aimed at educating women in Sudan include building schools, establishing teaching programmes and trying to influence local populations in favour of allowing women to learn formally. What they don't do is build wells. Unfortunately this means that despite their best efforts, women still won't attend school. Why? Because we are told by Sudanese women that they are traditionally waterbearers, and water is rarely available directly in population centres. Therefore women must spend hours every day marching off to, and back from, water sources - hours that, absent dying of thirst, cannot be diverted to education so long as water remains so inconveniently located. A USAID Disaster Assistance 
Response Team (DART) found similar conditions in Ethiopia. In June 2005 a DART reported, 'In rural Ethiopia, women and children typically walk two or more hours a day to collect water... trips of up to eight hours a day, as well as overnight journeys, in search of other water sources are not uncommon...Furthermore, time-consuming water gathering forces many girls to drop out of school in order to provide water for their families.' (USDS 2005) Unfortunately, the discovery of these kinds of cross-sector linkages is rare, as they are dependent entirely upon the insight of a few enlightened individuals rather than inherent in process. Furthermore, current bureaucratic apparatus are poorly suited to respond to recommendations that cut across sectors. The implications of this example are profound for the development community, both bureaucratically and programmatically. To succeed, the consideration of even singular issues must include the totality of the environment in which the issue is meant to be resolved. Like land tenure, critical path mapping is a particularly helpful tool that leads us across traditional bureaucratic boundaries to a solution that first shapes the environment (introduces water sources at population centres) so as to best enable direct assistance inputs (schools, books, supplies, teachers, et cetera) to actually succeed (women show up for class). The implications are so profound because, in the case of this example of women's education, women's education policy experts and programming officers must ostensibly be enlightened enough to recognize the need for, and ultimately engage in, seemingly unrelated infrastructure construction, or any other sector advancement that precludes their own aims.

The United Nations Development Group/World Bank 'Transitional Results Matrices' guide even uses female literacy as an example of how to create a 'Transitional Results Matrix', their version of a critical path map. The guide serves as the perfect illustration of gaps in current thinking. The 'baseline' of the UNDG/WB example is a 'literacy rate lower than 30\%' and 'damage to school infrastructure'. The proposed 'Actions' are 'teacher training, curriculum development' and 'publishing textbooks'. The 'Outputs' are 'teachers trained, textbooks delivered, schools built', with final 'Outcomes: Increased access to primary education; Increase in net enrolment; Increase in literacy rate' (UNDG/ WB 2005: 13) Yet we know, from the above example that it is highly probable that Sudan will not realize any of these outcomes unless the requirement of fetching water is removed from the equation. In the UNDG/WB guide, neither the receptiveness of an environment to inputs, nor the idea that fundamental barriers to development aims exist outside of a narrow functional subset, are introduced. Like the CSIS Task Framework, the functional divisions of the TRM virtually guarantee that the environment into which development aid will be channelled will never be properly considered. 


\section{Asset-Based Feedback Loops}

An important aspect of environment-shaping is the recognition of trendproducing mechanisms. In every society the potential for a positive feedback loop exists. Both political and material instruments of change - key people, associations ${ }^{5}$ or particular physical elements - also exist in every society. The current deficit-based approach to development modelling, an approach that focuses on absences and weaknesses, is inherently constrained to actions that ignore both the importance of building or repairing feedback loops and the change agents that make these loops relevant. In fact, the resulting 'imposition' of aid following deficit-based needs assessments often mobilizes change agents against seemingly sensible inputs by the 'benevolent developer' (UN/WB 2004). The Africans themselves tell the development community: 'Externally driven post-conflict reconstruction processes that lack sufficient local ownership and participation are unsustainable. They cause resentment and fail to integrate the underlying socio-cultural belief systems that shape the worldview of the internal actors.' (NEPAD 2005: 20)

Therefore, development approaches must recognize unique in situ feedback loop attributes and their associated change agents, and empower those agents to capitalize on the trend-creating effects of feedback loops, thus shaping the environment to maximize receptiveness to the most appropriate direct and indirect inputs.

\section{Feedback Loops}

The idea of feedback loops - most widely applied in control technology - is that the output of a system affects the next input and so on. This is how trends are created (Richardson 1986). A few people wear a certain brand of clothing, and more people see the clothing and wear it themselves. Still more people see the brand, now that many more people are wearing it, and so on, until virtually everyone is wearing this one brand of clothing. This is a 'positive' (that is, selfamplifying, as opposed to a moral judgment) feedback loop, because it is selfreinforcing. ${ }^{6}$ Tautologically, the more people buy the brand, the more people buy the brand. Of course, positive feedback loops can also be highly destructive and, left unchecked in physical systems, can have catastrophically destabilizing effects. In the development context, a positive feedback loop can reinforce destructive behaviour, such as deforestation, crime or violent conflict, just as it can reinforce constructive behaviour, such as economic activity, environmental conservation and racial tolerance. Without positive feedback loops growth, be it economic, social or physical, cannot take place. 


\section{Asset-Based Analysis}

Asset-based development analysis, often referred to as 'Asset-Based Community Development' or 'ABCD', focuses on what a community, town, city, nation, et cetera possesses rather than what it lacks. A town, for example, cannot promote growth with what it does not have. $A B C D$ seeks to identify the resources available to a community and to use those resources as the means to positive and productive ends. Some have argued that participatory approaches inherent to $A B C D$ are simply a clever way of co-opting communities to perform the wishes of outside 'developers'. The authors of this essay do not entirely disagree, but believe that combining the knowledge, experience and expectations of both internal and external actors is critical to achieving effective development solutions. Kretzmann and McKnight note in their ABCD guide that:

Focusing on the assets of lower income communities does not imply that these communities do not need additional resources from the outside. Rather, this guide simply suggests that outside resources will be much more effectively used if the local community is itself fully mobilized and invested, and if it can define the agendas for which additional resources must be attained. The assets within lower income communities, in other words, are absolutely necessary but usually not sufficient to meet the huge development challenges ahead. (Kretzmann and McKnight 1993: 7) ${ }^{7}$

While the UNDG and the World Bank seem in agreement with Kretzmann and McKnight over the tension between external and internal estimations, a careful reading reveals that UNDG and the World Bank twist 'participation' to mean adoption of their predetermined solution, stressing the need to successfully sell development programmes to the appropriate recipient constituency:

Balancing this tension between the principle of selectivity and the principle of
national ownership requires managing the trade-off between prioritization and
'buy-in'; creating a process which allows national stakeholders to define
ownership as participation and involvement rather than as development of a
TRM that includes all of their national priorities... national ownership cannot
and does not require one-hundred percent national consensus; rather, ownership
runs along a spectrum of participation, dialogue, sharing information, contribu-
tion, and sufficient agreement between key stakeholders to ensure that a
transitional process will not be derailed ... building and maintaining ownership is
a dynamic process, one that involves persuading new groups to support a reform
program as its net benefits become clear ... and offers quick benefits to groups
that are potential constituencies for further reforms, and undertake those
actions using a process that increasingly broadens the circle of participation in,
and support for, the reform agenda. (UNDG/WB 2005: 4-5, emphasis added)

Furthermore, the efforts at 'buy-in' called for in the TRM focus almost exclusively on governing elites, and not on the ultimate recipients of development assistance, even in those instances where foreign assistance is not delivered directly to the people. Consistent with USAID practices, the basis of a TRM is a 'post-conflict needs assessment', or PCNA, in which deficits rather 
than assets drive development programming. For example, 'Section G' is titled 'Using needs assessments as a platform for developing the TRM' (UNDG/WB 2005: 11). Anyone with experience implementing development programmes in a 'dynamic' environment understands the need to obtain 'buy-in' but, despite a call to put 'national counterparts' in the 'drivers seat' from the beginning' (UNDG/WB 2005: 5), it is unreasonable to conclude that the priorities and potential of aid recipients are likely to be well represented in a TRM. Similarly, while the NEPAD African Post-Conflict Reconstruction Policy Framework's 'emphasis on internal actors is based on the recognition that development processes cannot succeed without internal actors taking ownership of the postconflict reconstruction process' (NEPAD 2005: 21), the NEPAD framework fails to distinguish between participation in the sense of 'internal actors' simply accepting the assessment and desires of donors with little or no input of their own, and an inclusive process that calls for collaboration with internal actors in identifying and utilizing their specific strengths and assets to participate in their own growth, development and peace-building. Of the four prominent postconflict and development strategy documents this essay examines - CSIS, UNDG/ World Bank, USAID and NEPAD - none treat 'internal actors' as anything more than recipients of direct and indirect assistance, rather than as the ultimate implementers of a shared vision.

One of the most obvious examples of the consequences of a needs-based approach is in transnational wildlife-rich areas such as throughout Southern Africa. Because of the value of the flora and fauna in these regions to their tourist industries, countries such as South Africa, Namibia, Botswana, Mozambique, Zimbabwe and Swaziland make the preservation of 'natural' or 'wilderness' areas a national prerogative. Unfortunately preserved conservation areas are also perfect for refugees and for conducting illicit activities such as smuggling drugs, arms and endangered species of plants and animals. To counter refugees and smugglers countries such as Mozambique and Zimbabwe build fences because they create natural chokepoints and are easier to patrol. In the face of continued smuggling and refugee flows these countries perceive a 'deficit' of security measures, especially in wilderness areas, and the response has been heavier fences, which in turn further partitions the very wilderness areas these security measures are often designed to protect. This unfortunately destructive feedback loop looks something like this: more fragmented wilderness areas stress habitat in turn stressing the animals that live there, resulting in lesser wildlife tourism satisfaction, reducing wildlife tourism revenue, thereby diminishing income to alienated indigenous groups especially in or near protected areas who increase poaching to make up for falling incomes, which results in a need for yet more 'security' measures like fences, or even more extreme measures like war. Though clearly an undesirable feedback loop, this is exactly what is happening.

Both asset-based and deficit-based planners recognize that environmental degradation - a by-product of current approaches to security - can trigger violent conflict. An asset-based approach to the tension between the need for uninterrupted wildlife habitat and border security produces the 'transnational 
park', ${ }^{8}$ a result very different than that of traditional deficit-based approaches. Precisely the same transnational attributes of wildlife habitat that challenge the deficit-based planner instead appear as extraordinary opportunities for peacemaking to the asset-based planner. Environmental security experts like Dabelko and Konca argue that environmental challenges ignore political boundaries, require long-term thinking, encourage local and non-governmental participation, and extend community building. They propose that cooperation across boundaries may help to enhance trust, establish cooperative habits, create shared regional identities around shared resources, and establish mutually recognized rights and expectations (Dabelko and Conca 2002). The examples that Dabelko and Conca cite as environmental peacemaking, such as 'peace parks' (South Africa), shared river basin management plans (West and Central Africa), regional seas agreements (Mediterranean), and joint environmental monitoring programmes (Amazon Basin), are also examples of the result of asset-based thinking capitalizing on inherent opportunities for peace-building by collectively identifying with a shared challenge.

Once development planners recognize the power of existing or potential positive feedback loops, the effectiveness of an asset-based approach becomes apparent. The design or enhancement of a positive feedback loop requires identifying those elements that have the potential to magnify intended outcomes. By focusing not just on 'passive' enablers, but also on 'active' magnifiers, only an asset-based approach to development assessment can fulfil this requirement. The failure of current development methodologies to fully account for the necessity to match direct and indirect inputs to receptive environments, or seek to make environments more receptive to these same inputs otherwise, is the natural result of deficit-based 'needs' assessments. In contrast, an environment-shaping model takes advantage of the full spectrum of assets available to a community, region or nation, while recognizing its needs, not just to achieve 'buy-in', but to identify and build positive feedback loops based on the motivations, wishes and capabilities of the community itself.

\section{Information as a Policy Driver: Closing the Feedback Loop}

We have seen how environment-shaping is dependent on feedback loops. As a result, policy and programme design must account for perception management from the very beginning. A feedback loop by definition requires the transmission of information, whether deliberately or incidentally. This is true for all feedback loops, including those present in a development or post-conflict setting. For asset-based positive feedback loops to translate into meaningful trends, trendreinforcing information must find its way to those whose individual behaviour will result in shifts in collective attitude, and, ultimately, collective behaviour. If a particular attitude is attractive enough it may catch on by itself, but development planners cannot afford to leave the success of feedback loops to fate and must aggressively apply resources to reinforce positive trends. 
Within the US government, the military leads in the institutionalization of information used to enhance tactical or operational efforts. ${ }^{9}$ Civil Affairs (CA) and Psychological Operations (PSYOPS) units employ information operations widely. Information Operations are the totality of planned operations to convey select information and indicators to foreign audiences to influence the emotions, motives, objective reasoning and, ultimately, the behaviour of foreign governments, organizations, groups and individuals. Information Operations are a vital part of the broad range of US diplomatic, informational, military and economic activities. Information operations are characteristically employed with the intent to affect an outcome, as opposed to simply inform. When properly employed in a military setting, Information operations can save the lives of friendly and/or adversarial forces by reducing an adversary's will to fight or by communicating one's own forces friendliness to the local population.

Other agencies within the US government do not generally employ information as a 'tactical' component of operations, but instead treat information separately from policy formulation, issuing press releases and holding press conferences after a policy has been implemented. Public Affairs (PA) and Public Diplomacy (PD) offices are usually employed to deal with the unintended aftermath of a given policy action. An environment-shaping methodology demands the inverse: information and perception management must drive policy planning.

'Actions speak louder than words' is never truer than in international development. Development programmes must be designed so as to reinforce their own success. Aid donors must acknowledge the fundamental value of feedback loops by designing programmes that build on the positive perceptions revealed by an asset-based development approach. In practice this turns the conventional use of information on its head. Instead of designing a programme and then figuring out how to market it, the message communicated by a programme drives the decision whether to fund and implement it to begin with. Though the terms 'information operations' and 'psychological operations' may evoke propagandists, the asset-based approach called for by an environmentshaping methodology guarantees that the recipients of the 'message' have self-selected the message to begin with. In this way, environment-shaping is selfreinforcing, not just as a matter of process, but of content as well.

\section{Conclusion}

Despite years of experience with 'fragile states' and post-conflict reconstruction projects, the policy community engaged in these enterprises remains without a clear bridge from strategic desires to operational reality. In a scathing exercise of self-reflection the Joint Utstein Study of Peacebuilding (Smith 2004) concluded that of 336 peace-building projects conducted by the original 'U4' Utstein Group countries, Germany, United Kingdom, Norway and the Netherlands: 
55 percent of the projects do not show any link to a broader strategy for the country in which they are implemented ... Various security and socio-economic projects seem 'strategy resistant' as if they need no strategic justification because their worth is self-evident. Planning is based on relatively little analysis, and there are important conceptual confusions and uncertainties. (Smith 2004: 10-11)

Neither the results of other countries' development efforts, nor the personal experiences of these authors would indicate that any other donor nation, not the least the United States (USDS/USAID 2003), can claim to be an exception to the discoveries of the ' $U 4$ '.

Feckless performances rebuilding or permanently stabilizing nations in trouble reveal 'donor nations' policy makers' apparent inability to come to terms with either the limits to, or the nature of, their influence in fragile and post-conflict environments. Worse, there is scant evidence that this same community possesses a clear understanding of the factors that influence change on the societal or national levels. If such an understanding does exist, it has never been expressed in a form useful for policy practitioners.

This essay does just that by integrating several important existing strategic planning and development concepts into a new operational methodology that explicitly recognizes: the need of donors to concentrate on indigenous resources - material, social or individual; the wastefulness of allocating 'direct assistance' to an environment that is not receptive to effectively using those resources; therefore, the necessity to both adapt to, and seek to transform, the environment into which resources are put; and the inestimable role that perceptions play in the success or failure of development programmes at all levels, global to individual.

Environment-shaping thus begins by establishing long-term expectations (often referred to as 'end state') through strategic objectives. An asset-based participatory analysis follows. It is from this approach that all else stems, since only through the use of this approach can planners fully assess the nature of the environment they hope to improve. Stunningly, despite years of wasting billions of dollars with few successes to highlight, asset-based approaches remain largely anathema to the development community. But, similarly, the dividends asset-based approaches make possible cannot be fully realized until planners have accepted the overwhelming contribution information and perception management can make to their programme's success. Environment-shaping moves beyond the 'build it and they will come' mentality so common in today's development community and instead recognizes the primacy of aid recipients' perceptions and desires in determining how aid allocations will contribute to growth, stability and development. Environment-shaping capitalizes on existing, or cultivates new, positive feedback loops within a community, society or nation to guarantee that key enablers are best taken advantage of to promote localized development programmes to national development trends.

Environment-shaping's reliance on objective-driven critical path mapping prevents traditional narrowly bifurcated bureaucracies from developing 
operational plans that reflect more of themselves than the people and places they are trying to help. Critical path mapping within an environment-shaping approach emphasizes integrated multi-sector planning as a requirement for success. As a result, aid agencies' success is dependent on rewarding bureaucracies responsible for the design and implementation of development programming (and other aspects of programme design such as public affairs and diplomacy offices) for successfully contributing to fulfilling key objectives by breaking through traditional bureaucratic 'stovepipes'. Agency and bureau leadership should establish an institutional identity derived from mission objectives rather than the other way around. If necessary these organizations' structures must be reformed to best enable objective-driven rather than functionally- or geographically-driven policy and programme development. Furthermore, agencies and their leadership must be willing to press budget systems at the highest levels to facilitate the formation of programmes derived from the demand identified in the intelligent analysis of operational requirements 'on the ground', rather than simply from domestic budgetary supply.

Not just a strategy in the absence of strategy, environment-shaping is a profound challenge to the traditional approach to development programme planning because an environment-shaping methodology addresses not just aid itself, but the environment in which that aid will be delivered. By tightly relating direct and indirect assistance to its recipient environment, or shaping the recipient environment when necessary, environment-shaping can maximize the potential for success. Furthermore, as environment-shaping is holistically objective-driven, it not only ignores traditional barriers to successful aid programmes, but provides the means both to identify, and relate operationally any critical element of relevance to the objective regardless of what sector that element is normally associated with. No existing development strategy both comprehensively accounts for the relationship between development assistance and its recipient environment, identifies the nature of self-reinforcing or 'sustainable' mechanisms, and the power of perceptions in creating success.

\section{Acknowledgements}

The views expressed in this essay are solely those of the authors and do not reflect the views or policies of the US Government.

Notes

1 The Roland Paris 'Institutionalization before Liberalization' thesis (IBL) is based on evidence that the introduction of liberalization and electoral democratization into delicate national situations may often have the unintended consequence of contributing to, or even catalyzing, destabilization. Therefore, Paris suggests that: 'peacebuilders should continue to seek to transform war-shattered states into liberal market democracies, but with a different technique - by constructing the foundations of effective 
political and economic institutions before the introduction of electoral democracy and market-oriented adjustment policies' (2004: 79). He concludes that: 'Peacebuilders should delay liberalization and limit political and economic freedoms in the short run, in order to create conditions for a smoother and less hazardous transition to market democracy - and durable peace - in the long run' (187-8).

2 USAID has begun to reflect its understanding of this important point by shifting bureaucratic weight from a geographically-driven enterprise to one organized more functionally.

3 The authors recognize that mapping a critical path may reveal results in conflict with donors' national security interests. Though the methodology presented in this paper does not specifically address how planners might technically overcome this conundrum, the methodology presented here does enable the identification of conflicting interests that might have gone unnoticed otherwise. Once presented with the facts, senior decisionmakers and appropriators can evaluate courses of action with more complete information than in the absence of a sound planning methodology.

4 Alexis de Tocqueville recognized, especially in Democracy in America (1956) that in contrast to Europe, in the United States common people and not just elites gathered together in small self-appointed groups to solve problems, develop new approaches to production, and affirm the local society. These associations involved citizens in three processes:

a. Deciding, or identifying what is a problem

b. Deciding how, or whether or not to solve the problem

c. Organizing themselves and others to implement the solution.

5 In 1975 Levin, Roberts and Hirsch best captured the common definition of a positive feedback loop as one in which 'an initial change in any factor eventually induces further self-change in the original direction' (1975: 7).

6 See further, Dewar, Kretzman and McKnight (1997); for a more detailed critique of 'participatory' approaches see Cooke and Kothari (2001); and for a storied defence of participation in development see Samuel and Giles (2004).

7 For further background on Transnational Parks see: http://www. peaceparks.org.

8 The only reference to 'shaping the environment' these authors found in any source is in a small number of US military documents including an undefined usage of the term in the 1996 Quadrennial Defense Review, and a more operationally specific usage in several Joint publications regarding Information and Psychological Operations: 'PSYOP shall be employed routinely by combatant commanders to shape the operational environment during peacetime' (USMJP 2003:VI-4). In fact, Army Civil Affairs projects such as building schools and wells, or providing much needed medical care comes closest to true 'environment-shaping', since these activities are almost always engaged in with the strategic aim of 'winning hearts and minds'.

\section{References}

Cooke, B. and Kothari, U. (eds) (2001) Participation: The New Tyranny? New York: Zed Books.

CSIS (2002) Center for Strategic and International Studies, Post-Conflict Reconstruction: Task Framework, May. Washington, DC: Association for the US Army and Center for Strategic and International Studies.

Dabelko, G. and Conca, K. (2002) Environmental Peacemaking. Baltimore, MD: Johns Hopkins University Press.

De Soto, H. (2000) The Mystery of Capital. New York: Basic Books. 
De Tocqueville, A. (1956) Democracy in America. New York: Mentor Books.

Dewar, T., Kretzmann, J. P. and McKnight, J. A. (1997) Guide To Evaluating Asset-Based Community Development: Lessons, Challenges, and Opportunities. Chicago, IL: ACTA Publications.

InterAction (2004) InterAction seminar, 'Status of Southern Sudan Development Planning', USAID Official Rappateur's notes, Washington, DC, November.

Kretzmann, J. P. and McKnight, J. A. (1993) Building Communities from the Inside Out: A Path Toward Finding and Mobilizing a Community's Assets. Chicago, IL: ACTA Publications.

Levin, G., Roberts, E. and Hirsch, G. (1975) The Persistent Poppy: A Computer-aided Search for Heroin Police. Cambridge, MA: Ballinger Publishing Co.

Lockyer, K. G. (1964) An Introduction to Critical Path Analysis. London: Pitman Publishing.

NEPAD (2005) New Partnership for Africa's Development Secretariat; Governance, Peace and Security Programme, African Post-Conflict Reconstruction Policy Framework. New Partnership for Africa's Development (NEPAD), June. Accessed at: http://www. africanreview.org/docs/conflict/PCR\%20Policy\%20Framework.pdf.

Paris, R. (2004) At War's End: Building Peace After Civil Conflict. Cambridge: Cambridge University Press.

Richardson, G. (1986) 'Problems with Causal-Loop Diagrams', Systems Review, 2:2, 158-70.

Samuel, H. and Giles, M. (eds) (2004) Participation - From Tyranny to Transformation?: Exploring New Approaches to Participation in Development. New York: Zed Books.

Smith D. (2004) Overview Report of the Joint Utstein Study of Peacebuilding, Towards a Strategic Framework for Peacebuilding: Getting Their Act Together. Oslo: International Peace Research Institute, January. Accessed at: http://www.dep.no/filarkiv/210673/ rapp104.pdf.

UNDG/WB (2005) United Nations Development Group and World Bank, An Operational Note on Transitional Results Matrices; Using Results-Based Frameworks in Fragile States. January. Accessed at: http://www.oecd.org/dataoecd/29/18/34245139.pdf.

UN/WB (2004) United Nations and World Bank, Practical Guide to Multilateral Needs Assessments in Post-Conflict Situations, August. Accessed at: http://lnweb18. worldbank.org/ESSD/sdvext.nsf/67ByDocName/PracticalGuidetoMultilateralNeedsAsse ssmentsinPost-ConflictSituationAJointUNDGUNDPandWorldBankGuidepreparedbyGTZwi ththesupportofBMZ/\$FILE/PCNA.Tool.pdf.

USAID (2005) US Agency for International Development, Fragile States Strategy, January. Washington, DC: US Agency for International Development. Accessed at: http:// www.usaid.gov/policy/2005_fragile_states_strategy.pdf.

USDS (2005) US Department of State, unclassified cable: Addis Ababa 2140, 17 June.

USDS/USAID (2003) US Department of State and US Agency for International Development, Strategic Plan Fiscal Years 2004-2009, Washington, DC, August. Accessed at: http:// www. revistainterforum.com/english/pdf_en/24299.pdf.

USIP (2005) United States Institute of Peace, 'The Coalition Provisional Authority's Experience with Economic Reconstruction in Iraq: Lessons Identified', USIP Special Report, 138, April. Washington, DC: USIP.

USMJP (2003) Doctrine for Joint Psychological Operations, 5 September. US Military Joint Publication, 3-53. Accessed at: http://www.iwar.org.uk/psyops/resources/us/jp3_53. pdf.

WB et al. (2005) World Bank, International Finance Corporation and Oxford University Press, Doing Business in 2005: Removing Obstacles to Growth. Washington, DC: World Bank. Accessed at: http://www.doingbusiness.org/documents/DoingBusiness2005.pdf. 